\title{
Detection of surface-adsorbed (lipo)proteins by means of a two-step enzyme-immunoassay: A study on the Vroman effect
}

\author{
A. Poot,* T. Beugeling, W. G. van Aken, and A. Bantjes \\ University of Twente, Dept. CT, P.O. Box 217, 7500 AE Enschede, The Netherlands
}

In view of reports on the involvement of high-molecular-weight (HMW) kininogen and high-density lipoprotein (HDL) in the Vroman effect, we studied the adsorption of fibrinogen, HMW kininogen, HDL and several other proteins from pooled human plasma and congenitally HMW kininogendeficient plasma onto glass and low-density polyethylene, both as a function of the plasma concentration and the contact time. Mixtures of purified (lipo)proteins were also included in the study. Protein adsorption was determined by means of a two-step enzyme-immunoassay. Our results support the hypothesis that HMW kininogen is involved in the displacement of fibrinogen, which is almost instantly adsorbed from normal plasma onto glass. On hydrophobic polymers like polyethylene, the low amounts of adsorbed fibrinogen and HMW kininogen from plasma and concentrated plasma solutions may be due to a preferential adsorption of HDL.

\section{INTRODUCTION}

One of the first events which take place after blood is exposed to an artificial surface is the adsorption of proteins. Subsequent cellular interactions with the surface will be largely determined by the amount, nature, and conformation of the adsorbed proteins. Adsorption experiments in which mixtures of purified albumin, $\lg G$, and fibrinogen were used, revealed a preferential adsorption of fibrinogen. ${ }^{1,2}$ It has become clear, however, that data concerning the adsorption of proteins from relatively simple solutions may not be extrapolated to the adsorption of proteins from multicomponent mixtures such as plasma.

Studies by Vroman et al. ${ }^{3,4}$ have shown that initially adsorbed fibrinogen from plasma onto hydrophilic glass-like surfaces is no longer immunologically detectable after a few minutes of contact time. This "conversion" was markedly delayed in plasma lacking high-molecular-weight (HMW) kininogen, which suggests that initially adsorbed fibrinogen on hydrophilic surfaces is replaced by HMW kininogen. When hydrophobic substrates were incubated with normal plasma, "conversion" of fibrinogen was not observed. Using ${ }^{125} \mathrm{I}$-fibrinogen it was shown by Brash and ten Hove, ${ }^{5}$ that

*To whom correspondence should be addressed.

Journal of Biomedical Materials Research; Vol. 24, 1021-1036 (1990)

(C) 1990 John Wiley \& Sons, Inc.

CCC 0021-9304/90/081021-16\$04.00 
"conversion" indeed refers to displacement of initially adsorbed fibrinogen with increasing contact time. Moreover, displacement of fibrinogen was not observed when $1: 1000$ diluted plasma was used. It has been suggested by Vroman, ${ }^{5}$ that by diluting plasma sufficiently the concentration of HMW kininogen decreases to such a low value that adsorbed fibrinogen cannot be replaced anymore.

Several authors have reported ${ }^{2,5-7}$ that the adsorption of fibrinogen from serial dilutions of plasma onto both hydrophilic and hydrophobic surfaces shows a maximum at a plasma dilution of $1: 100-1: 1000$. As proposed by Horbett, ${ }^{7}$ both this plasma dilution effect and the above mentioned "conversion" process are called the "Vroman effect."

The effect of plasma dilution on the adsorption of fibrinogen may be explained in terms of displacement of initially adsorbed fibrinogen by HMW kininogen at high plasma concentrations (Vroman, see above). However, Breemhaar et al. ${ }^{2}$ have suggested that a preferential adsorption of HDL may also contribute to the low adsorption of fibrinogen (and other proteins) from undiluted plasma onto polymer surfaces like PVC and polystyrene.

The present study deals with the involvement of HMW kininogen and HDL in the Vroman effect. By means of a two-step enzyme-immunoassay we studied the adsorption of fibrinogen, HMW kininogen, HDL and several other proteins from plasma onto glass and polyethylene, both as a function of the plasma concentration and the contact time. Moreover, the fibrinogen adsorption from HMW kininogen-deficient plasma and from mixtures of purified (lipo)proteins was examined.

\section{MATERIALS AND METHODS}

\section{Test device}

The two-step enzyme-immunoassay was performed in a test device (Fig. 1) consisting of a stainless-steel bottom plate provided with nine screw pins and a teflon upper part containing 24 cylindrical holes with a diameter of $10 \mathrm{~mm}$. Between the bottom plate and the upper part either a polymeric film $(13 \times 9 \mathrm{~cm})$ or two glass plates $(5 \times 9 \mathrm{~cm})$ were placed, after which the device was put together with wing nuts. Leakage from the wells was prevented by 24 silicon rubber sealing rings which were fitted in between the test surface and the teflon upper part. The test surface area and the contents of each well were $0.9 \mathrm{~cm}^{2}$ and $800 \mu \mathrm{L}$, respectively.

\section{Test surfaces}

Low-density polyethylene sheets (Talas, Ommen, The Netherlands) with a thickness of $0.05 \mathrm{~mm}$ were ultrasonically cleaned for $15 \mathrm{~min}$ in a $1 \%(\mathrm{v} / \mathrm{v})$ detergent solution (RBS 25, Hicol, Rotterdam, The Netherlands), followed by extensive rinsing with distilled water and ethanol, respectively. 


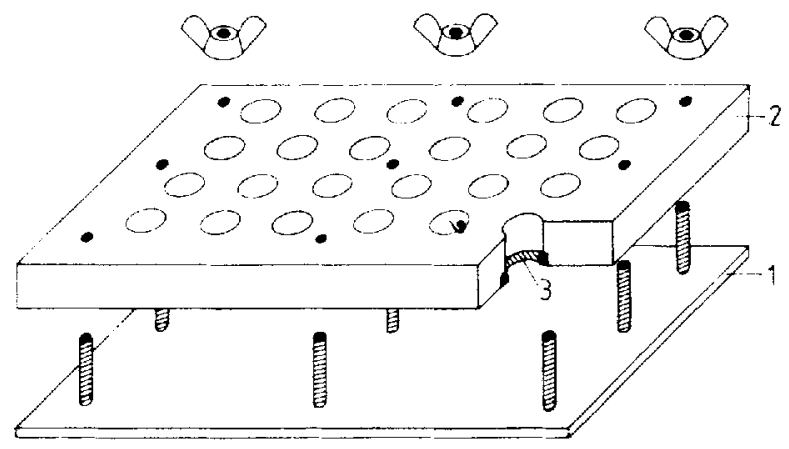

Figure 1. Test device for two-step enzyme-immunoassay. (1) Stainless-steel bottom plate; (2) Teflon upper part; (3) silicone rubber sealing ring.

Glass plates (hard glass type 7059, Corning, New York, USA) with a thickness of $2 \mathrm{~mm}$ were cleaned by immersion during $15 \mathrm{~h}$ in a mixture of fuming hydrochloric acid $(100 \mathrm{~mL})$ and fuming nitric acid $(33 \mathrm{~mL})$, followed by extensive rinsing with distilled water and ethanol, respectively. Before use, the polyethylene sheets and glass plates were air-dried. These two cleaning treatments are routinely used in our laboratory and have previously been shown, e.g., by means of water contact angle measurements before and after treatment, to be effective. ${ }^{8}$

\section{Plasma and purified plasma proteins}

In preliminary experiments using single-donor plasmas, protein adsorption was found to be dependent on the plasma batch used, presumably due to differences in protein concentrations. To avoid the use of plasmas with an abnormally high or low concentration of a certain protein, we used pooled plasma which might be expected to contain physiological concentrations of each protein. Blood from 15 healthy male donors was anticoagulated with $130 \mathrm{mM}$ sodium citrate; the anticoagulant to blood ratio was 1:9 (v/v). Plasma was prepared by centrifugation $(15 \mathrm{~min}$ at $1570 \mathrm{~g}$, followed by $15 \mathrm{~min}$ at $3000 \mathrm{~g}$ ), pooled and stored at $-30^{\circ} \mathrm{C}$.

Human fibrinogen was obtained from Kabi (Grade L, Stockholm, Sweden) and further purified by chromatography on aminohexyl-Sepharose $4 \mathrm{~B}$ (Pharmacia, Uppsala, Sweden) as previously described. ${ }^{9}$ The purified fibrinogen preparation was extensively dialysed against PBS, concentrated by dehydration against Sephadex 200 (Pharmacia) and stored in aliquots $(28 \mathrm{mg} / \mathrm{mL})$ at $-30^{\circ} \mathrm{C}$. The fibrinogen concentration was determined using A280 $\mathrm{nm}, 1 \mathrm{~cm}, 1 \%=15.5 .^{10}$ The purified fibrinogen was more than $98 \%$ clottable $\left(5 \mathrm{U} / \mathrm{mL}\right.$ thrombin, $\left.10 \mathrm{~min}, 37^{\circ} \mathrm{C}\right)$. Before use, the purified fibrinogen was centrifuged for $5 \mathrm{~min}$ in an Eppendorf centrifuge in order to remove possible aggregates. 
Lipoproteins were isolated from human plasma by density gradient ultracentrifugation according to Redgrave et al. ${ }^{11}$ with some modifications. Fresh plasma (from a single donor) was prepared from blood anticoagulated with $1 / 10$ volume of $130 \mathrm{mM}$ sodium citrate as described above. After addition of the protease inhibitor phenylmethylsulphonylfluoride $(0.1 \mathrm{mM})$ and $0.1 \%$ $\mathrm{NaN}_{3}, 50 \mathrm{mg}$ sucrose and $770 \mathrm{mg} \mathrm{KBr}$ were dissolved in $2 \mathrm{~mL}$ plasma in a polycarbonate tube. Subsequently, solutions of $\mathrm{KBr}$ and $\mathrm{NaCl}$ with densities of respectively $1.21(2.6 \mathrm{~mL}), 1.10(3 \mathrm{~mL}), 1.019(2 \mathrm{~mL})$, and finally distilled water $(2 \mathrm{~mL}$ ) were added. After ultracentrifugation (Sorvall SW $40 \mathrm{Ti}$, $36000 \mathrm{rpm}, 20 \mathrm{~h}, 15^{\circ} \mathrm{C}$ ), fractions of $0.5 \mathrm{~mL}$ were collected of which the density was determined by means of a Mettler/Paar DMA 45 density meter provided with a DMA $602 \mathrm{M}$ density measuring cell. The HDL and LDL containing fractions were pooled, extensively dialysed against PBS and stored at $4^{\circ} \mathrm{C}$ after filtration through a $0.2 \mu \mathrm{m}$ filter (Flow Laboratories, Herts, UK). The apo A1 (HDL) and apo B (LDL) concentrations were determined according to Havekes et al. ${ }^{12,13}$ and amounted to $0.70 \mathrm{mg} / \mathrm{mL}$ and $0.75 \mathrm{mg} / \mathrm{mL}$, respectively.

A $20 \%$ solution of human serum albumin (HSA), containing less than $5 \%$ $\alpha$ - and $\beta$-globulines, was obtained from the Central Laboratory of the Netherlands Red Cross Blood Transfusion Service (CLB, Amsterdam).

Purified native (single chain) HMW kininogen $(0.6 \mathrm{mg} / \mathrm{mL})$ and congenitally HMW kininogen-deficient plasma (George King Biomed. Inc., Overland Park, USA) were kindly provided by Dr. B. N. Bouma (Dept. of Haematology, University Hospital, Utrecht, The Netherlands). The purified HMW kininogen preparation has been extensively characterized. ${ }^{14}$

\section{Enzyme-immunoassay reagents}

Rabbit sera directed against human fibrinogen, fibronectin, factor VIII, IgG, HSA and apo B (LDL) were obtained from the CLB. Rabbit serum directed against human apo A1 (HDL) was purchased from Behringwerke AG (Marburg, FRG). Purified goat antibody $(1.8 \mathrm{mg} / \mathrm{mL})$ directed against the light chain of human HMW kininogen was kindly provided by Dr. F. van Iwaarden (Dept. of Haematology, University Hospital, Utrecht, The Netherlands). Before use in the enzyme-immunoassay, appropriate dilutions of the antisera $(1: 100$, except for anti-apo $A 1$ which was diluted $1: 10)$ and the antiHMW kininogen solution $(1: 2000)$ were made in first antibody buffer consisting of $150 \mathrm{mM} \mathrm{NaCl}, 50 \mathrm{mM}$ Tris, $0.2 \%(\mathrm{w} / \mathrm{v})$ gelatin (Merck, Darmstadt, FRG), $0.02 \%(\mathrm{w} / \mathrm{v})$ Tween-20 (Sigma, St. Louis, MO), $0.5 \%(\mathrm{w} / \mathrm{v})$ bovine serum albumin (BSA, Sigma), pH 7.5.

Sheep anti-rabbit IgG and rabbit anti-goat IgG both conjugated to horseradish peroxidase were obtained from United States Biochemical Co. (Cleveland, $\mathrm{OH}$ ). These conjugates were diluted 1:200,000 and 1:6,000, respectively, in conjugate buffer, which had the same composition as the first antibody buffer except for a 10-fold higher concentration of BSA $(5 \%)$. When glass was used as the substrate for the adsorption of proteins, high 
blank values of the enzyme-immunoassay (see next section) were observed due to a high nonspecific adsorption of the enzyme-labeled sheep antirabbit IgG, which could be prevented by replacing the 5\% BSA in the conjugate buffer for $10 \%$ normal sheep serum (CLB).

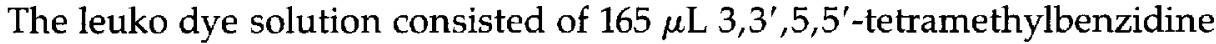
(Fluka AG, Buchs, Switzerland) $(6 \mathrm{mg} / \mathrm{mL}$ DMSO) and $10 \mathrm{~mL} 0.11 \mathrm{M}$ sodium acetate/citric acid $\mathrm{pH}$ 5.5. Shortly before use, $10 \mu \mathrm{L}$ of a $3 \% \mathrm{H}_{2} \mathrm{O}_{2}$ solution was added as the enzyme substrate.

\section{Protein adsorption and enzyme-immunoassay procedure}

The entire procedure was carried out at room temperature. In order to prevent the formation of an air-liquid-solid interface which may induce protein denaturation, the 24 wells of the test device were filled with $200 \mu \mathrm{L}$ PBS. Subsequently, $200 \mu \mathrm{L}$ plasma, protein solution or dilutions of these in PBS were added. Wells which were filled with $400 \mu \mathrm{L}$ PBS were used as blanks. During pipetting of the test samples, the end of the pipettor tip did not touch the test surface and was kept under the liquid surface. After gently mixing using the pipettor, the wells were covered with tape. The wells were also covered after the successive steps of the enzyme-immunoassay procedure.

At selected times, the protein solutions were removed and the test surfaces were rinsed four times with $800 \mu \mathrm{L}$ PBS containing $0.005 \%(\mathrm{w} / \mathrm{v})$ Tween-20. This rinsing solution was also used after the subsequent steps. Next, the wells were filled with $200 \mu \mathrm{L}$ first antibody solution. After $1 \mathrm{~h}$, the wells were rinsed four times and subsequently $200 \mu \mathrm{L}$ peroxidase-labeled second antibody was applied. Contact time was again $1 \mathrm{~h}$.

After rinsing two times, the Teflon upper part of the test device was replaced by a clean one in order to prevent the detection of protein which had been adsorbed to the inner walls and the sealing rings. Subsequently, the surfaces were rinsed two more times after which the wells were filled with $200 \mu \mathrm{L}$ substrate/leuko dye solution. The enzymatic color reaction was carried out in the dark for $30 \mathrm{~min}$ and was terminated by addition of $100 \mu \mathrm{L} 4 \mathrm{~N}$ sulphuric acid. Part of the dye solution $(250 \mu \mathrm{L})$ was transferred into a well of a 96 wells plate (A/S Nunc, Roskilde, Denmark) and the absorbance was measured at $450 \mathrm{~nm}$ by means of a multiscanner (Reader Micro Elisa System, Organon Teknika, Turnhout, Belgium).

\section{RESULTS}

\section{Protein adsorption from normal pooled plasma}

Protein adsorption from serial dilutions of normal pooled plasma to polyethylene and glass after a contact time of $1 \mathrm{~h}$ is shown in Figures $2 \mathrm{a}, \mathrm{b}$ and $3 a, b$, respectively. Except for the adsorption isotherms of HDL on poly- 

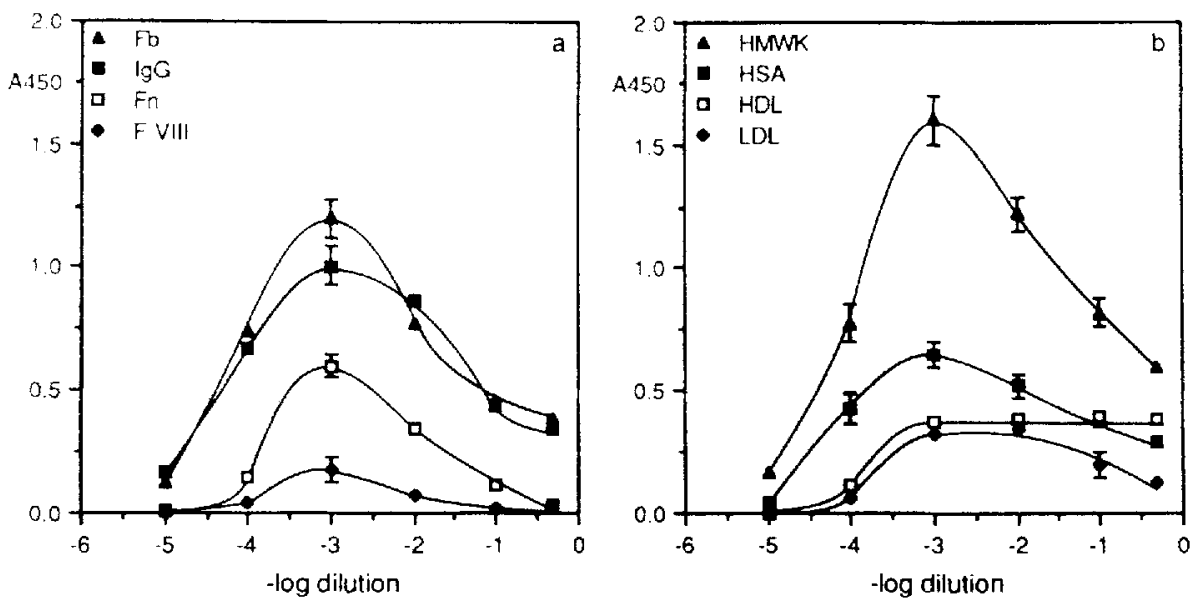

Figure 2. Adsorption of (a) fibrinogen ( $\mathrm{Fb}$ ), IgG, fibronectin (Fn), factor VIII (F VIII), and (b) HMW kininogen (HMWK), HSA, HDL, LDL, from normal pooled plasma onto polyethylene as a function of the plasma dilution at a contact time of $1 \mathrm{~h}$. All values are expressed as mean \pm SD $(n=4)$. The absence of error bar indicates that the standard deviation of the data was smaller than the size of the symbol.

ethylene and HMW kininogen on glass which reach plateau values at high plasma concentrations, all other isotherms show adsorption maxima at plasma dilutions of $1: 100-1: 1000$.

The adsorption kinetics of fibrinogen, HDL, and HMW kininogen from $1: 1$ and 1:1000 diluted plasma to polyethylene are shown in Figures $4 a, b$
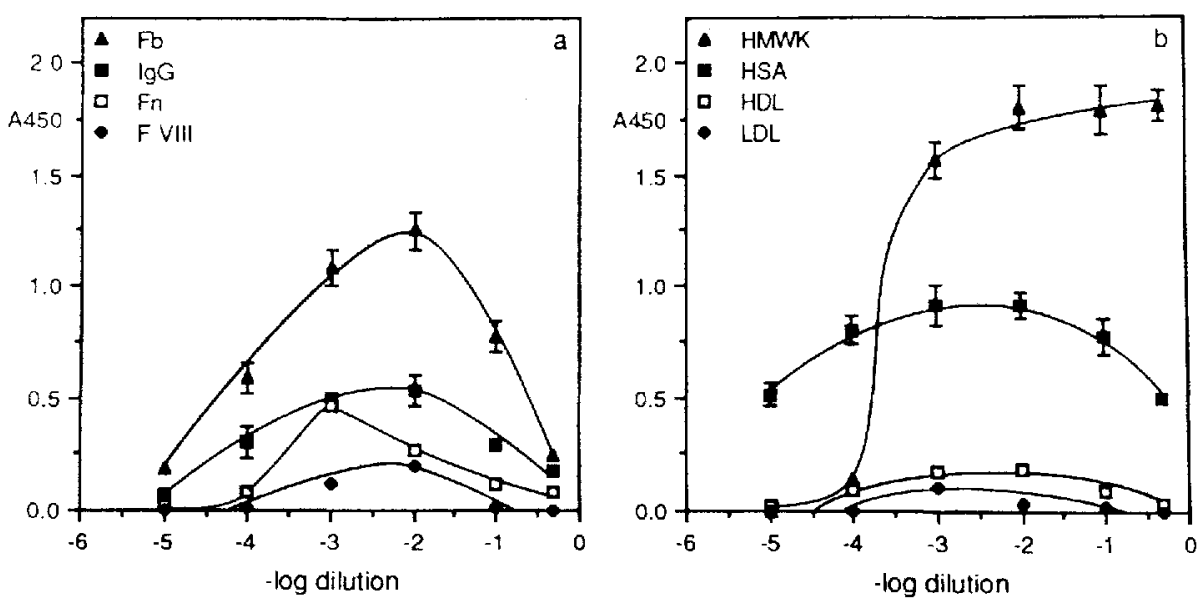

Figure 3. Adsorption of (a) Fb, IgG, Fn, F VIII and (b) HMWK, HSA, HDL, LDL from normal pooled plasma onto glass as a function of the plasma dilution at a contact time of $1 \mathrm{~h}$. All values are expressed as mean $\pm \operatorname{SD}(n=4)$. The absence of error bar indicates that the standard deviation of the data was smaller than the size of the symbol. 

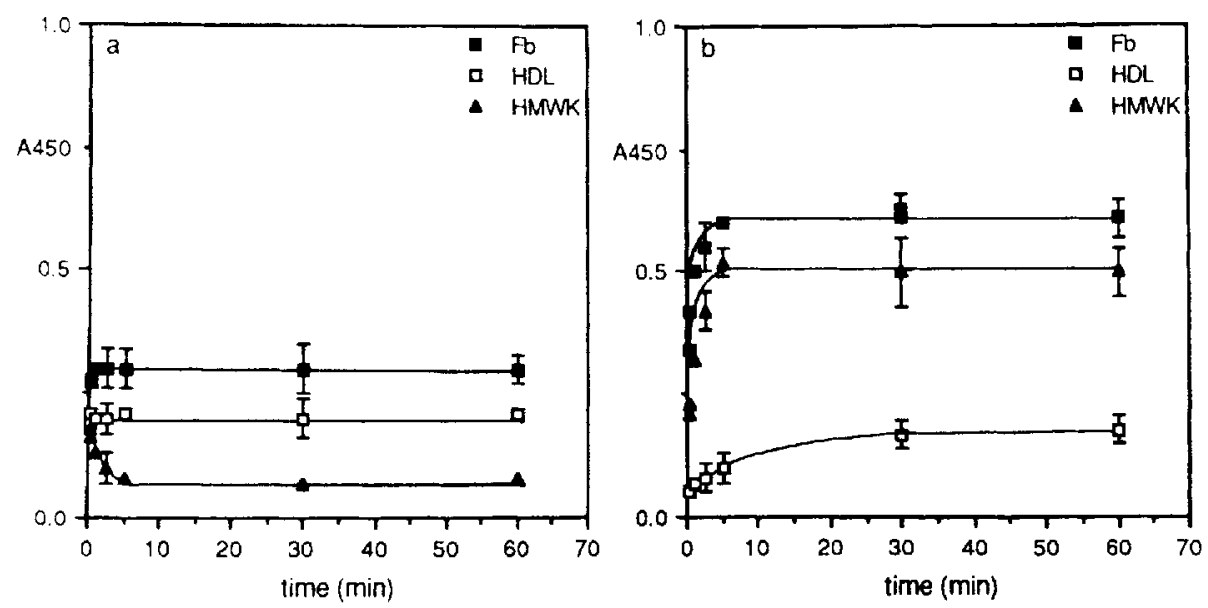

Figure 4. Adsorption kinetics of $\mathrm{Fb}, \mathrm{HDL}$ and HMWK from (a) 1:1 and (b) 1:1000 diluted normal pooled plasma onto polyethylene. All values are expressed as mean $\pm \operatorname{SD}(n=4)$. The absence of error bar indicates that the standard deviation of the data was smaller than the size of the symbol.

respectively. When 1:1 diluted plasma was used, plateau values for the adsorption of both fibrinogen and HDL were reached within $1 \mathrm{~min}$ of contact time. Adsorption kinetics of fibrinogen and HDL from 1:1000 diluted plasma showed that plateau values were reached after 5 and 30 min of contact time respectively. When polyethylene was incubated with $1: 1$ diluted plasma, the amount of initially adsorbed HMW kininogen decreased during the first minute of contact time and stabilized thereafter. However, when 1:1000 diluted plasma was used the adsorption of HMW kininogen increased with increasing contact time and reached a plateau after $5 \mathrm{~min}$. The steady-state adsorption of both fibrinogen and HMW kininogen from 1:1000 diluted plasma to polyethylene was higher than from 1:1 diluted plasma, whereas at both plasma dilutions the plateau values for the adsorption of HDL were similar. Note that the absolute values of the A450 measurements shown in Figures 2 and 3 are higher than those depicted in the subsequent figures, which is due to a decrease of the enzymatic activity of the peroxidaselabeled second antibody over a period of several months (see Discussion).

The adsorption kinetics of fibrinogen, HDL, and HMW kininogen from 1:1 and 1:1000 diluted plasma to glass are shown in Figures 5a,b, respectively. When 1:1 diluted plasma was used, the amounts of initially adsorbed fibrinogen and HDL decreased during the first few minutes of contact time and stabilized thereafter, whereas the adsorption of HMW kininogen almost instantly reached a plateau. Adsorption kinetics of fibrinogen and HDL from 1:1000 diluted plasma showed that plateau values were reached after $10 \mathrm{~min}$ of contact time while the adsorption of HMW kininogen increased with increasing contact time up to $60 \mathrm{~min}$. The steady-state adsorption of both fibrinogen and HDL from 1:1000 diluted plasma to glass was higher than from 1:1 diluted plasma. Moreover, during the entire con- 

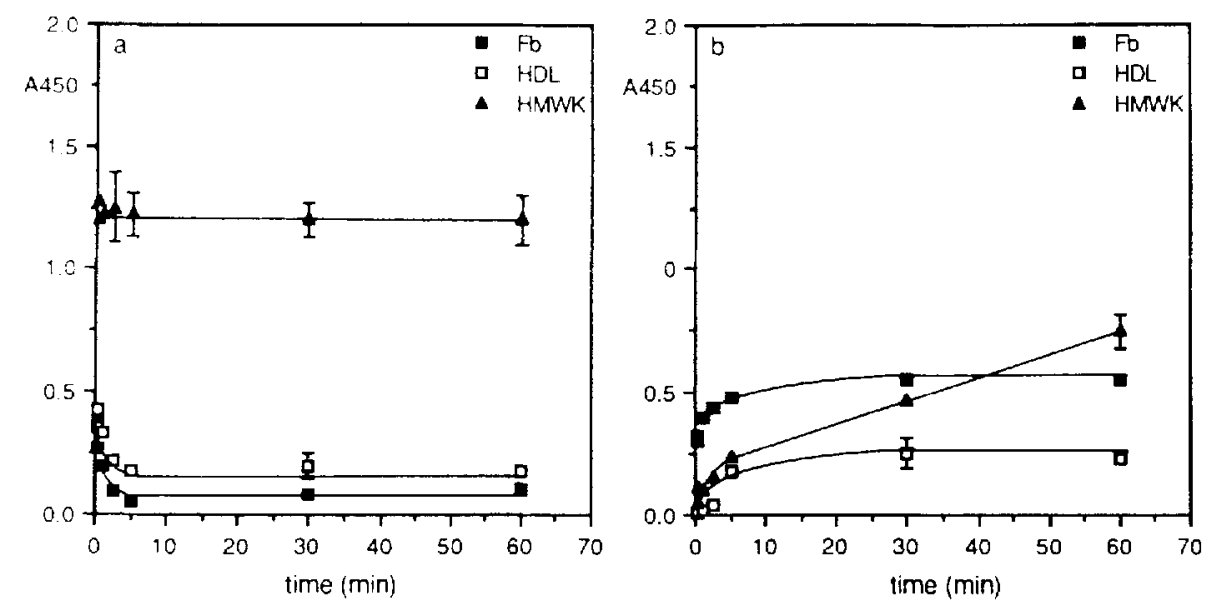

Figure 5. Adsorption kinetics of $\mathrm{Fb}, \mathrm{HDL}$, and HMWK from (a) $1: 1$ and (b) $1: 1000$ diluted normal pooled plasma onto glass. All values are expressed as mean $\pm \mathrm{SD}(n=4)$. The absence of error bar indicates that the standard deviation of the data was smaller than the size of the symbol.

tact time of $60 \mathrm{~min}$ the adsorption of HMW kininogen from 1:1 diluted plasma was higher than from 1:1000 diluted plasma.

\section{Protein adsorption from HMW kininogen-deficient plasma}

The fibrinogen adsorption from serial dilutions of HMW kininogendeficient plasma to glass after a contact time of $1 \mathrm{~h}$ showed an adsorption maximum at a plasma dilution of $1: 100-1: 1000$ as was observed with normal plasma (Fig. 6a). At a plasma dilution of 1:1, the adsorption of fibrinogen from HMW kininogen-deficient plasma was higher than from normal plasma. Moreover, the decrease of the amount of initially adsorbed fibrinogen with increasing contact time, as was observed with $1: 1$ diluted normal plasma, was markedly less when HMW kininogen-deficient plasma was used (Fig. 6b). The fibrinogen adsorption from HMW kininogen-deficient plasma to polyethylene was not significantly different compared to the adsorption from normal plasma (see Figs. $2 a$ and $4 a$ ).

\section{Protein adsorption from mixtures of purified proteins}

When polyethylene was incubated for $1 \mathrm{~h}$ with serial dilutions of mixtures containing fibrinogen and either HDL, LDL, HSA, or HMW kininogen, only the mixture of fibrinogen and HDL showed a significant decrease of the fibrinogen adsorption with increasing protein concentration (Figs. 7a-d).

When similar experiments were carried out with glass as a substrate for the adsorption of proteins, none of the mixtures showed a significant de- 

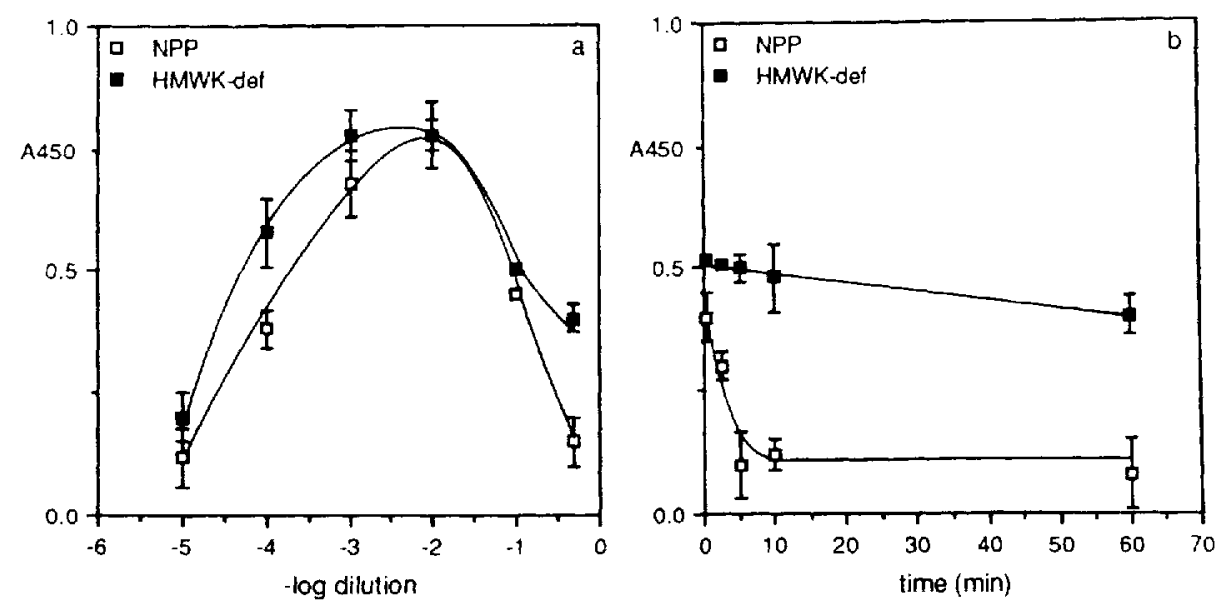

Figure 6. (a) Adsorption of $\mathrm{Fb}$ from normal pooled plasma (NPP) and HMWK-deficient plasma (HMWK-def) onto glass as a function of the plasma dilution at a contact time of $1 \mathrm{~h}$ and (b) adsorption kinetics of $\mathrm{Fb}$ from 1:1 diluted NPP and HMWK-deficient plasma onto glass. All values are expressed as mean $\pm \mathrm{SD}(n=4)$. The absence of error bar indicates that the standard deviation of the data was smaller than the size of the symbol.

crease of the fibrinogen adsorption with increasing protein concentration (Figs. 8a-d).

\section{DISCUSSION}

In the present study the adsorption of proteins was detected by means of a modified version of the two-step enzyme-immunoassay which has been developed by Breemhaar. ${ }^{15}$ By using specific antibodies in the first step of the assay, the method allows a very simple and fast detection of a variety of adsorbed (lipo)proteins from complex mixtures such as plasma. Moreover, the enzyme-immunoassay is very sensitive compared to other detection methods. ${ }^{15}$ A limitation of the technique is that the detection of adsorbed (lipo)proteins is only semiquantitative.

The procedure as originally described by Breemhaar was changed in several respects. In the present study the test surfaces were wetted with PBS before protein adsorption was initiated in order to prevent the formation of an air-liquid-solid interface which may lead to the deposition of a layer of denatured proteins (16). By using dilution buffers which differed in composition ${ }^{17}$ from those in the original procedure, a lower non-specific adsorption of either first antibody or enzyme-labeled second antibody has been obtained. Due to these changes in the dilution buffers the concentration of Tween-20 in the washing buffer could be reduced tenfold, thereby diminishing the risk of desorption of hydrophilic proteins adsorbed to hydrophobic substrates. ${ }^{15}$

Using this modified procedure, we studied the adsorption of fibrinogen, fibronectin, factor VIII, IgG, HSA, HDL, LDL, and HMW kininogen from 

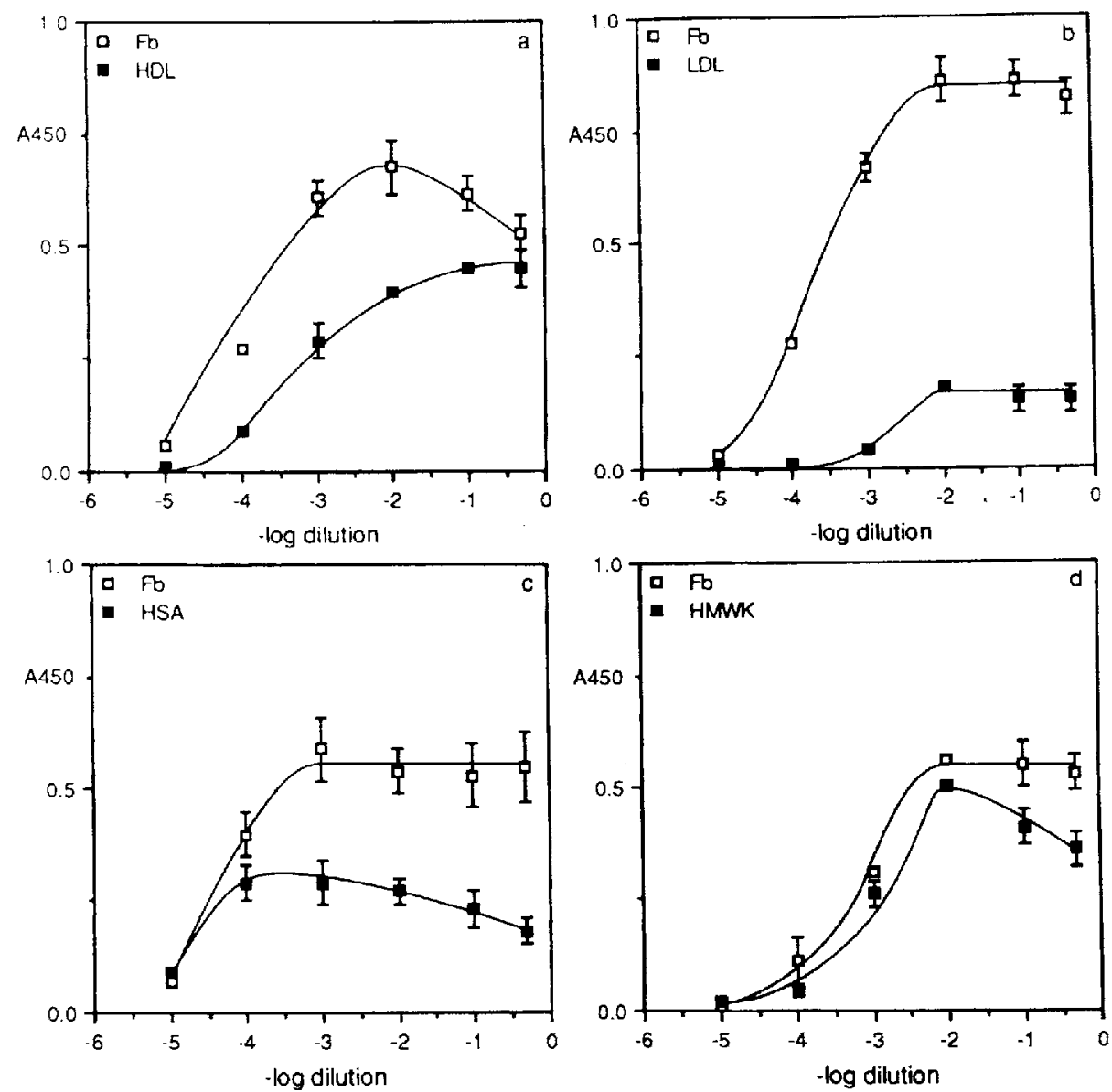

Figure 7. Protein adsorption from mixtures containing $\mathrm{Fb}(3 \mathrm{mg} / \mathrm{mL})$ and either (a) HDL (0.62 mg apo A1/mL), (b) LDL (0.66 mg apo B/mL), (c) HSA $(40 \mathrm{mg} / \mathrm{mL})$, or (d) HMWK $(70 \mu \mathrm{g} / \mathrm{mL})$ onto polyethylene at a contact time of $1 \mathrm{~h}$. All values are expressed as mean $\pm \mathrm{SD}(n=4)$. The absence of error bar indicates that the standard deviation of the data was smaller than the size of the symbol.

serial dilutions of normal pooled plasma onto glass and polyethylene. It was found that except for the adsorption isotherms of HMW kininogen on glass and HDL on polyethylene which reached plateau values at high plasma concentrations, all other isotherms showed adsorption maxima at plasma dilutions of $1: 100-1: 1000$. Similar isotherms for the adsorption of fibrinogen, IgG, HSA, and HDL on PVC and polystyrene; fibrinogen on glass and polyethylene; ${ }^{5-7}$ and fibronectin on polystyrene ${ }^{18}$ have been reported.

The high level of the adsorption plateau for HMW kininogen on glass and the high adsorption maximum for HMW kininogen on polyethylene does not necessarily reflect an increased surface concentration of HMW kininogen, 

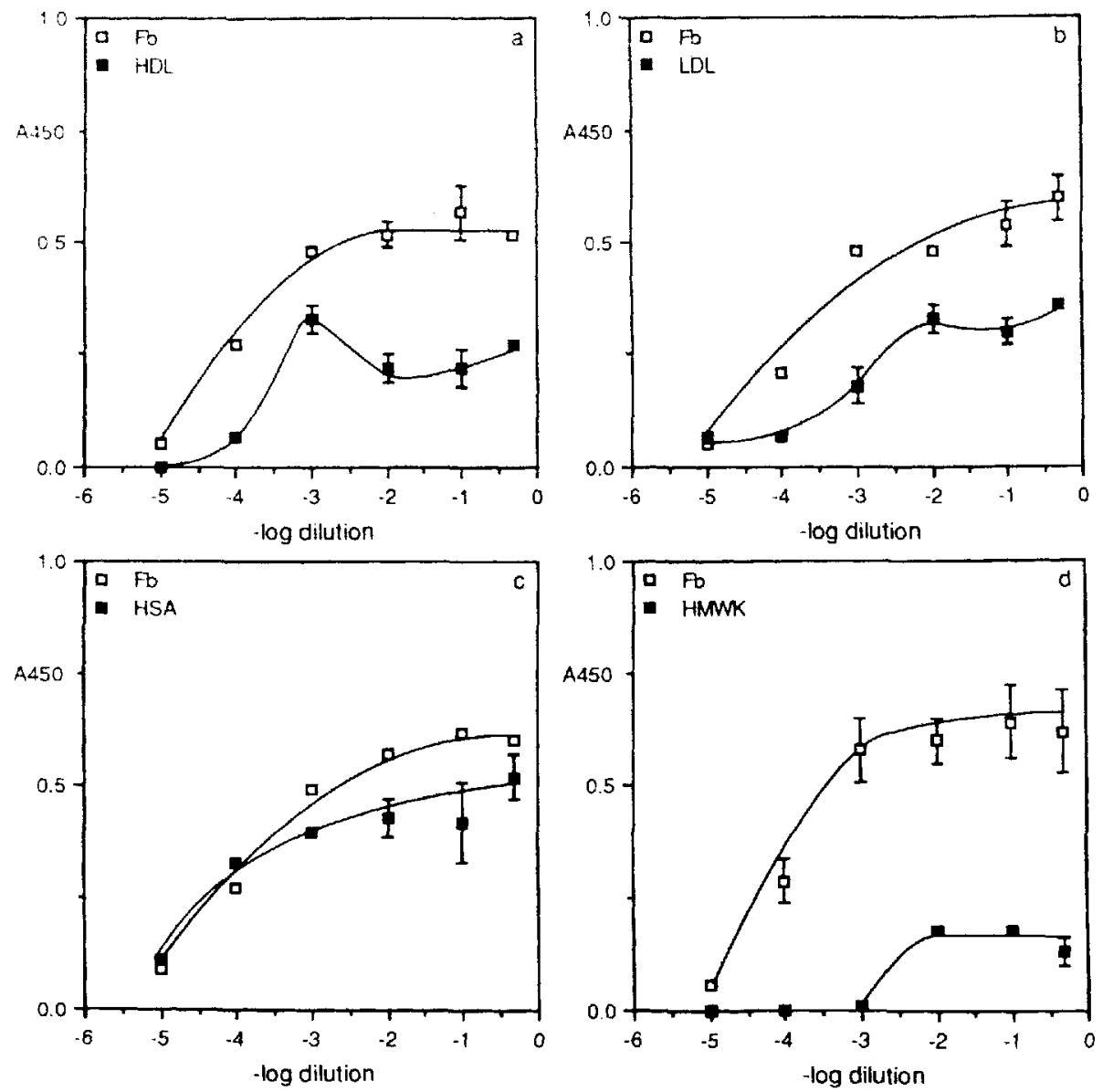

Figure 8. Protein adsorption from mixtures containing $\mathrm{Fb}(3 \mathrm{mg} / \mathrm{mL})$ and either (a) HDL (0.62 mg apo A1/mL), (b) LDL (0.66 mg apo B/mL), (c) HSA $(40 \mathrm{mg} / \mathrm{mL})$ or (d) HMWK $(70 \mu \mathrm{g} / \mathrm{mL})$ onto glass at a contact time of $1 \mathrm{~h}$. All values are expressed as mean $\pm \mathrm{SD}(n=4)$. The absence of etror bar indicates that the standard deviation of the data was smaller than the size of the symbol.

but may be due to the use of different kinds of first antibody and conjugate as compared to the antibodies used for the detection of the other proteins. For the same reason, the low adsorption plateau for HDL on polyethylene may be due to the use of a different kind of first antibody (see Materials and Methods). It has to be emphasized that the enzyme-immunoassay is only semiquantitative: one may not extrapolate differences in A450 determined for distinct proteins, to differences in the actual amounts of the proteins present on the surface. Moreover, a decrease of the enzymatic activity of the peroxidase-labeled second antibody in course of time (several months) gives rise to differences in the absolute values of the A450 measurements 
for a certain protein in identical experiments. This inconsistency may be overcome by simultaneous determination of the protein adsorption from a standard protein solution each time an enzyme-immunoassay is performed.

Adsorption kinetics showed that the amount of initially adsorbed fibrinogen from 1:1 diluted normal plasma onto glass decreased with increasing contact time, whereas the adsorption of HMW kininogen almost instantly reached a plateau. Moreover, the "conversion" of initially adsorbed fibrinogen onto glass was markedly less when 1:1 diluted HMW kininogen-deficient plasma was used. Thus, our results with respect to the adsorption of fibrinogen from plasma onto glass, both as a function of the plasma concentration and the contact time, are in agreement with the concept that HMW kininogen is involved in the displacement of initially adsorbed fibrinogen. In 1:1000 diluted normal plasma the concentration of HMW kininogen is decreased below effective levels to displace fibrinogen. This is supported by our kinetic data for the fibrinogen adsorption from 1:1000 diluted plasma onto glass, which show that the adsorption of fibrinogen increases with increasing contact time until a plateau is reached.

It must be mentioned that Slack and Horbett ${ }^{19}$ and Slack et al. ${ }^{20}$ found no significant differences in the adsorption of fibrinogen from normal human plasma and HMW kininogen-deficient plasma onto glass after $2 \mathrm{~h}$ at $37^{\circ} \mathrm{C}$. However, the latter authors ${ }^{20}$ also reported enhanced fibrinogen adsorption onto glass from HMW kininogen-deficient plasma relative to that from normal plasma if the experiment was performed for $5 \mathrm{~min}$ at $25^{\circ} \mathrm{C}$. These findings indicate the importance of the experimental conditions, most probably the contact time, in studies regarding the Vroman effect.

HMW kininogen circulates in plasma non-covalently complexed with prekallikrein and factor XI. Upon exposure of plasma to a surface which initiates contact activation (e.g., glass), HMW kininogen binds to the surface thereby facilitating the proteolytical activation of prekallikrein and factor XI by surface activated factor XII. ${ }^{21}$ The generated kallikrein in turn will enzymatically activate more factor XII. In addition, kallikrein has been shown to cleave HMW kininogen resulting in the liberation of bradykinin and the formation of two-chain HMW kininogen, ${ }^{22}$ which has an increased ability to bind to the surface. ${ }^{23}$ Brash et al. ${ }^{24}$ recently presented evidence that this kallikrein-activated HMW kininogen is the active component in the Vroman effect. Furthermore, they showed that upon digestion by activated factor XI, the activity of HMW kininogen in the Vroman effect was lost. Our results which show that the adsorption of purified fibrinogen to glass is not affected by the presence of purified single-chain HMW kininogen, are in agreement with these findings.

The results reported in this paper do not indicate that HMW kininogen is involved in the displacement of fibrinogen which is adsorbed onto polyethylene. On the contrary, adsorption kinetics presented here show that when polyethylene is incubated with 1:1 diluted normal plasma, the adsorption of fibrinogen reaches a plateau, whereas the amount of initially adsorbed HMW kininogen decreases with increasing contact time. These results are in agreement with the original qualitative observation reported by Vroman 
et al., "that fibrinogen is "converted" on hydrophilic but not on hydrophobic surfaces. Using the same qualitative technique, Schmaier et al. ${ }^{25}$ showed that after incubation of plasma for $10 \mathrm{~min}$ on glass, adsorption of HMW kininogen was detectable whereas no adsorption of fibrinogen could be observed. When PVC was used, however, fibrinogen was present on the surface whereas HMW kininogen was not detectable. Similar results have been obtained by Elwing et al. ${ }^{26}$ using ellipsometry on oxidized and silanized silicon.

Our results indicate that the low adsorption of fibrinogen (and other proteins) from plasma onto polyethylene may be due to a preferential adsorption of HDL. Except for the adsorption isotherm of HDL on polyethylene which reached a plateau, the isotherms of all other proteins studied showed adsorption maxima at plasma dilutions of 1:100-1:1000. Adsorption isotherms of fibrinogen, which were obtained by incubating polyethylene and glass with serial dilutions of a mixture of fibrinogen and HDL, only showed an adsorption maximum for fibrinogen when polyethylene was used. These findings extend the observations reported by Breemhaar et al., ${ }^{2}$ who showed similar maxima for the adsorption of fibrinogen when PVC and polystyrene were incubated with serial dilutions of a mixture of fibrinogen and HDL.

In summary, the data presented here are in agreement with the concept that HMW kininogen is involved in the displacement of fibrinogen, which is almost instantly adsorbed from normal plasma onto glass. On hydrophobic polymers like polyethylene the adsorption of fibrinogen at high plasma concentrations may be relatively low due to a preferential adsorption of HDL. Adsorption kinetics showed that the adsorption of both fibrinogen and HDL from 1:1 diluted plasma onto polyethylene reached a plateau, which indicates that initially adsorbed fibrinogen is not displaced by HDL. In this respect the tentative explanation of the Vroman effect which is given by Cuypers et al. ${ }^{27}$ might be relevant. These authors presented an adsorption model in which the equilibrium association constant of a certain protein is dependent on the overall surface concentration of adsorbed proteins, which is expressed by an interaction term. It was shown that due to differences in interaction terms for different proteins, the ratio of adsorbed proteins may be strongly dependent on the overall surface concentration, even if the ratio of the proteins in solution is kept constant (serial dilution).

According to Horbett, ${ }^{28}$ the Vroman effect is a characteristic feature of all mixed surfactant systems. Upon adsorption to a surface, proteins may undergo a transition from the native conformation to a denatured or "spread" state. Due to differences in the rate of transition for different proteins, initially adsorbed fibrinogen from plasma may be displaced from the surface by competing proteins which require more time to "spread" completely. At low plasma concentrations, the occupancy of available adsorption sites on the surface is low, and adsorbed fibrinogen may "spread" on the surface without competition from other proteins. Slack and Horbett recently reported ${ }^{19}$ that the adsorption of fibrinogen from binary mixtures of fibrinogen and Triton X-100, oxyhemoglobin, and albumin reaches a maximum at intermediate mixture dilutions, similar to the adsorption of fibrinogen from 
serial dilutions of plasma. Although these experiments were not physiologically relevant (e.g., requirement of an albumin to fibrinogen ratio of $100: 1$ ), the authors hypothesized that the Vroman effect may be due to the combined action of many surface-active proteins present in plasma. Our results show that the adsorption isotherms for common plasma proteins such as albumin, IgG, fibronectin, and factor VIII on both glass and polyethylene also reach maxima at intermediate plasma concentrations, which suggests that these proteins are displaced from the surface at high plasma concentrations. However, they may be actively involved in the Vroman effect by displacing each other. Using glass as a substrate for adsorption, Vroman and Adams ${ }^{29}$ found that proteins displace each other in the following sequence: albumin, IgG, fibrinogen, fibronectin, HMW kininogen, and factor XII. As shown in the present paper, this sequence is not likely for the adsorption of proteins from plasma onto hydrophobic polymers like polyethylene.

In order to account for the competition and "spreading" of adsorbing protein molecules in a kinetic model of protein adsorption, the protein/surface association "constants" should vary with the residence time of the proteins on the surface and should be dependent on the surface concentrations and adsorbing properties of competing proteins.

We wish to acknowledge the support of Drs. B. N. Bouma and F. van Iwaarden.

\section{References}

1. J.L. Brash and S. Uniyal, "Dependence of albumin-fibrinogen simple and competitive adsorption on surface properties of biomaterials," J. Polym. Sci., C66, 377 (1979).

2. W. Breemhaar, E. Brinkman, D. J. Ellens, T. Beugeling, and A. Bantjes, "Preferential adsorption of high density lipoprotein from blood plasma onto biomaterial surfaces," Biomaterials, 5, 269 (1984).

3. L. Vroman and A. L. Adams, "Findings with the recording ellipsometer suggesting rapid exchange of specific plasma proteins at liquid/solid interfaces," Surface Sci., 16, 438 (1969).

4. L. Vroman, A. L. Adams, G. C. Fischer, and P. C. Munoz, "Interaction of high molecular weight kininogen, factor XII and fibrinogen in plasma at interfaces," Blood, 55, 156 (1980).

5. J. L. Brash and P. ten Hove, "Effect of plasma dilution of adsorption of fibrinogen to solid surfaces," Thromb. Haemost. 51, 326 (1984).

6. P. Wojciechowski, P. ten Hove, and J. L. Brash, "Phenomenology and mechanism of the transient adsorption of fibrinogen from plasma (Vroman effect)," J. Colloid Interface Sci., 111, 455 (1986).

7. T. A. Horbett, "Mass action effects on competitive adsorption of fibrinogen from hemoglobin solutions and from plasma," Thromb. Haemost., 51, 174 (1984).

8. P. B. Van Wachem, "Interactions of cultured human endothelial cells with polymeric surfaces," PhD Thesis, University of Twente, Enschede, The Netherlands, 1987, p. 95.

9. A. Poot, T. Beugeling, J. P. Cazenave, A. Bantjes, and W. G. van Aken, "Platelet deposition in a capillary perfusion model: quantitative and morphological aspects," Biomaterials, 9, 126 (1988). 
10. R. F. Doolittle, "Fibrinogen," in CRC Handbook Series in Clinical Laboratory Science, section I, Hematology, Vol. III, D. Seligson and R. M. Schmidt (eds.), CRC Press, Boca Raton, 1980, p. 3.

11. T. G. Redgrave, D. C. K. Roberts, and C. E. West, "Separation of plasma lipoproteins by density-gradient ultracentrifugation," Anal. Biochem., 65, 42 (1975).

12. L. Havekes, C. M. van Gent, C.I. Stegerhoek, A. C. Arntzenius, and L. W. Hessel, "High density lipoprotein cholesterol and apoprotein A1 levels in 32-33 year old women on steroid contraceptives: differences between two frequently used low-estrogen pills," Clin. Chim. Acta, 116, 223 (1981).

13. L. Havekes, J. Hemmink, and E. de Witt, "Low density lipoprotein apoprotein $B$ in plasma as measured by radial immunodiffusion and rocket immuno-electrophoresis," Clin. Chem., 27, 1829 (1981).

14. F. Van Iwaarden, Ph. G. de Groot, J. J. Sixma, M. Berrettini, and B. N. Bouma, "High molecular weight kininogen is present in cultured human endothelial cells: localization, isolation and characterization," Blood, 71, 1268 (1988).

15. W. Breemhaar, "An enzyme-immunoassay for the detection of blood components adsorbed to polymeric surfaces," PhD Thesis, 1985, Twente University, Enschede, The Netherlands.

16. L. Vroman and A. L. Adams, "Why plasma proteins interact at interfaces," in Proteins at Interfaces: Physicochemical and Biochemical Studies, J. L. Brash and T. A. Horbett (eds.), American Chemical Society, Washington, 1987, p. 154.

17. J.G. Huisman, Central Laboratory of the Netherlands Red Cross Blood Transfusion Service, Amsterdam, personal communication.

18. F. Grinnell and T. V. Phan, "Deposition of fibronectin on material surfaces exposed to plasma: quantitative and biological studies," I. Cell Physiol., 116, 289 (1983).

19. S. M. Slack and T. A. Horbett, "Physicochemical and biochemical aspects of fibrinogen adsorption from plasma and binary protein solutions onto polyethylene and glass," J. Colloid Interface Sci., 124, 535 (1988).

20. S. M. Slack, J. L. Bohnert, and T. A. Horbett, Ann. N.Y. Acad. Sci., 516, 223 (1987).

21. A.P. Kaplan and M. Silverberg, "The coagulation-kinin pathway of human plasma," Blood, 70, 1 (1987).

22. D. M. Kerbiriou and J. H. Griffin, "Human HMW kininogen: studies of structure function relationships and of proteolysis of the molecule occurring during contact activation of plasma," J. Biol. Chem., 254, 12020 (1979)

23. C.F. Scott, L. D. Silver, M. Schapira, and R. W. Colman "Cleavage of high molecular weight kininogen markedly enhances its coagulant activity: evidence that this molecule exists as a profactor," J. Clin. Invest., 73, 954 (1984).

24. J. L. Brash, C.F. Scott, P. ten Hove, P. Wojciechowski, and R. W. Colman, "Mechanism of transient adsorption of fibrinogen from plasma to solid surfaces: role of the contact and fibrinolytic systems," Blood, 71, 932 (1988).

25. A. H. Schmaier, L. Silver, A. L. Adams, G. C. Fischer, P. C. Munoz, L. Vroman, and R.W. Colman "The effect of high molecular weight kininogen on surface-adsorbed fibrinogen," Thromb. Res., 33, 51 (1983).

26. H. Elwing, A. Askendal, and I. Lundström, "Competition between adsorbed fibrinogen and high molecular weight kininogen on solid surfaces incubated in human plasma (the Vroman effect): influence of solid surface wettability," J. Biomed. Mat. Res., 21, 1023 (1987). 
27. P. A. Cuypers, G. M. Willems, H.C. Hemker, and W. Th. Hermens, "Adsorption kinetics of protein mixtures: a tentative explanation of the Vroman effect," Ann. N.Y. Acad. Sci., 516, 244 (1987).

28. T. A. Horbett, "Adsorption to biomaterials from protein mixtures," in Proteins at Interfaces: Physicochemical and Biochemical Studies, J. L. Brash and T. A. Horbett (eds.), American Chemical Society, Washington, 1987, p. 239.

29. L. Vroman and A. L. Adams, "Adsorption of proteins out of plasma and solutions in narrow spaces," I. Colloid Interface Sci., 111, 391 (1986).

Received July 3, 1989

Accepted January 26, 1990 